\title{
AS ESPECIFICIDADES DO PADRÃO DE APEGO DE MENINOS: ESTUDO DE CASOS MÚLTIPLOS
}

\author{
SPECIFICITIES OF THE ATTACHMENT PATTERN OF BOYS: \\ MULTIPLE CASE STUDY
}

\author{
Michele Scheffel Schneider ${ }^{1}$ \\ Vera Regina Röhnelt Ramires ${ }^{2}$
}

Schneider MS, Ramires VRR. As especificidades do padrão de apego de meninos: um estudo de casos múltiplos. Rev Bras Cresc e Desenv Hum 2011; 21(2): 3296-306.

\section{RESUMO}

Esta pesquisa buscou identificar indicadores do padrão de apego de meninos em relação a suas figuras parentais, avaliar a existência de especificidade do padrão de apego em relação à mãe e ao pai e descrever as características familiares associadas ao apego seguro/inseguro. $\mathrm{O}$ estudo, realizado com três meninos entre 5 e 8 anos, com queixas escolares, foi baseado na teoria do apego e adotou como procedimento os Estudos de Casos Múltiplos. A avaliação dos indicadores do apego foi realizada através do Manchester Child Attachment Story Task - MCAST, procedimento cujas estórias remetem a situações de angústia. A análise do desfecho de cada narrativa apontou indicadores do padrão de apego implicado. Outros procedimentos foram aplicados, com a finalidade de complementar os dados encontrados no MCAST: Escala Global e Escala de Freqüência de Sinais Específicos aplicada ao Desenho da Família, Medical Outcomes Study (MOS) e Entrevistas com os meninos e seus pais. Em dois dos três casos avaliados se levantou a hipótese de especificidade do padrão de apego em relação à mãe e ao pai. A qualidade de cada relação parental foi única e um padrão de apego considerado como predominantemente seguro apresentou indicadores inseguros e vice-versa. As características familiares relacionaram-se a vínculos frágeis, presença de doenças na família, depressão materna e conflitos conjugais, todos relacionados a padrões inseguros de apego. O estudo também identificou uma diversidade das nomenclaturas que definem os principais conceitos do apego, um predomínio de literatura internacional e a necessidade de estudos brasileiros sobre a especificidade do apego.

Palavras-chave: apego; especificidade; meninos.

1 Psicóloga, Mestre em Psicologia pela UNISINOS - Universidade do Vale do Rio dos Sinos - UNISINOS - Avenida Unisinos, 950 / 93022-000 / São Leopoldo - RS

2 Doutora em Psicologia Clínica pela PUCSP, Professora, Pesquisadora e Coordenadora do PPG Psicologia da UNISINOS (vramires@unisinos.br) - Avenida Unisinos, 950 / 93022-000 / São Leopoldo - RS

Este artigo é parte da Dissertação de Mestrado intitulada: As especificidades do padrão de apego da criança em relação à figura materna e paterna, defendida em 22/08/08. A pesquisa foi realizada no Mestrado em Psicologia Clínica da Universidade do Vale do Rio dos Sinos - UNISINOS, orientada pela profa. Vera Regina Röhnelt Ramires.

Correspondência para: Michele Scheffel Schneider - Rua Walter Lamb, 145/503 - Bairro: São José / 93040-250. São Leopoldo - RS - Telefone: (51) 9109-9824 / (51) 3568-8782 fax. michelescheffel@gmail.com 


\begin{abstract}
This research sought to identify indicators of attachment pattern of boys related to their parental figures, to evaluate the existence of specificity in the attachment pattern related to mother and father so as to describe the families characteristics associated with the secure/ insecure attachment. The study included three boys aged between 5 and 8 years old with problems at school. It was based on the attachment theory and adopted the method of Multiple Cases. Attachment indicators evaluation was appraised through Manchester Child Attachment Story Task - MCAST, a procedure where histories are associated with anguish situation. The analyses of the outcomes of each narrative showed indicators of attachment patterns involved. Other procedures were applied with the objective of complement the data found through MCAST: Global Scale and Frequency Scale of Specific Signals applied to the Family's Drawing, Medical Outcomes Study (MOS) and Interviews with the boys and their parents. In two of the three cases evaluated the hypothesis of attachment specificity pattern related to mother and father was considered. The quality of each parental relationship was unique and the attachment pattern considered as predominant secure presented some insecure indicators and vice-versa. The family characteristics are related to weak attachments, the register of diseases in the family history, maternal depression and conjugal conflicts, all of them were related to the constitution of the attachment insecure patterns. This study also identified the nomenclature diversity that defines the mains attachment concepts, a predominance of international literature and a lack of Brazilian studies about specifics of the attachment.
\end{abstract}

Key words: attachment; specificity; boys.

\section{INTRODUÇÃO}

As variações do apego vêm sendo pesquisadas de modo crescente, em especial a partir do ano 2000, podendo-se identificar dois focos. Num deles, os pesquisadores buscam analisar a estabilidade ou variabilidade do padrão de apego ao longo do desenvolvimento do sujeito ${ }^{1-9}$. No outro, os estudos identificam a possibilidade do padrão de apego ser específico para cada relação emocionalmente significativa ${ }^{10-16}$.

A questão da variabilidade e especificidade do apego é considerada como uma das novidades mais importantes nesta temática nos últimos anos. Entende-se que a formação de novos vínculos de apego pode ser possível durante toda a vida, que o sistema de apego não é constituído unicamente nos primeiros anos de vida, mas sim está sujeito a transformações ao longo de todo o desenvolvimento. Ainda, determinadas condições podem mudar o estilo de apego e a cons- tituição do apego não depende somente da mãe, mas de ambos os pais, de todo sistema familiar, dos cuidadores, das relações de amizade e das relações com os parceiros amorosos ${ }^{2}$.

A possibilidade de variabilidade do padrão de apego diante das situações de vulnerabilidade, tais como a falta de cuidados constantes e organizados, os eventos de vida negativos como a morte de um dos pais, o divórcio parental, doença severa de algum dos pais ou da própria criança, as desordens psiquiátricas, abuso de drogas e de álcool na família, abuso físico e sexual já haviam sido levantadas por Bowlby ${ }^{17-18}$. Constata-se que $o$ precursor da teoria do apego, apesar de acreditar que determinados fatores poderiam prejudicar a estabilidade do modelo representacional interno, não desenvolveu o tema da especificidade do padrão de apego.

As pesquisas que se dedicaram a aprofundar o foco da variabilidade do padrão de apego nos últimos anos caracterizam-se 
por estudos longitudinais e apresentam resultados similares aqueles encontrados por Bowlby ${ }^{4-5,8-9,19}$. Em geral, essas pesquisas avaliaram o padrão de apego infantil através da Situação Estranha e, posteriormente, o padrão de apego adulto através da Entrevista de Apego Adulto (AAI).

No entanto, uma importante descoberta da teoria do apego foi apontar que o padrão de apego reflete a qualidade do relacionamento da criança com seu cuidador ${ }^{23}$. Assim, com o crescente desenvolvimento da teoria, alguns estudos buscam identificar a existência de uma possível especificidade do padrão de apego para relações emocionalmente significativas como, por exemplo, com a mãe, o pai ou outros cuidadores. ${ }^{10-13,16}$.

Os achados teóricos instigam um campo de pesquisa, afinal discutem a respeito dos primeiros vínculos afetivos da criança e seus cuidadores, relações estas fundamentais para o entendimento do desenvolvimento posterior, bem como a possibilidade de pensar estratégias preventivas e de promoção de saúde, em especial, na primeira infância.

Diante do exposto, os objetivos do estudo foram identificar indicadores do padrão de apego da criança em relação a suas figuras parentais, avaliar a existência de uma especificidade do padrão de apego em relação à mãe e ao pai e descrever as características familiares associadas ao apego seguro e/ou inseguro.

\section{MÉTODO}

\section{PARTICIPANTES}

O estudo foi pautado por uma abordagem qualitativa-exploratória, utilizando-se o procedimento de Estudo de Casos Múltiplos ${ }^{27}$. Foram avaliados três meninos entre cinco e oito anos e seus respectivos pais, que buscaram atendimento psicológico na Clínica-Escola de uma Universidade do sul do país. Optou-se em pesquisar os meninos por ser este o público infantil predominante do local. Utilizou-se o critério de saturação teórica para definição do número de participantes.

Os casos participantes da pesquisa preencheram os seguintes critérios de inclusão: ter pai e mãe biológicos vivendo junto, pelo menos um filho entre cinco e oito anos e no mínimo um dos pais estar exercendo atividade remunerada fixa, e de exclusão: famílias com indicadores de violência doméstica e/ou psicose e aquelas encaminhadas pelo Juizado da Infância e Juventude. Esses casos foram encaminhados pela escola com queixas referentes a dificuldades de relacionamento, agitação, insegurança e falta de limites. As famílias tinham renda familiar entre dois e três salários mínimos.

O projeto foi submetido ao Comitê de Ética em Pesquisa da Universidade, protocolo CEP 07/020 e aprovado em 24 de julho de 2007, Resolução 043/2007. Todos os participantes estavam informados a respeito do estudo, seus objetivos e procedimentos, concordando em participar e assinando o Termo de Consentimento Livre e Esclarecido.

\section{PROCEDIMENTOS PARA COLETA DE DADOS}

A coleta de dados ocorreu num momento anterior ao atendimento oferecido na instituição. A especificidade do apego, foco central do estudo, foi avaliada através do Manchester Child Attachment Story Task$M C A S T^{28}$. Os demais procedimentos utilizados tiveram a finalidade de complementar os dados encontrados no MCAST, reforçando-os ou refutando-os.

Inicialmente foi realizada com cada caso a Entrevista Familiar: contato inicial para explicar a pesquisa, escutar o motivo da consulta, fazer um levantamento da história e observar a dinâmica da família. Na sequência, foram realizadas Entrevistas individuais semiestruturadas com os pais e mães que tinham como objetivo identificar como as figuras 
parentais relacionam-se entre si, com seus próprios pais e com seus filhos, além de analisar as possíveis situações adversas ocorridas com a família. Nessas entrevistas foi aplicado o Medical Outcomes Study - MOS ${ }^{29}$ que buscava avaliar como os pais percebem sua rede de apoio e social.

O MCAST foi aplicado individualmente com cada menino, após as entrevistas com os pais. Trata-se de um procedimento composto de cinco estórias nas quais estão em casa apenas a criança e o cuidador que se quer avaliar. As estórias remetem a situações de angústia: na primeira vinheta a criança acorda sozinha durante a noite tendo um pesadelo; na segunda está brincando, cai e machuca o joelho, causando dor e sangramento; na terceira desenvolve uma dor de barriga intensa, na quarta discute com um amigo na escola e é rejeitada pelo mesmo antes de voltar para casa onde estão seus pais e, na quinta e última vinheta, se encontra perdida e sozinha enquanto faz compras numa grande loja.

Através do desfecho da narrativa proposto pela criança, da resposta do cuidador e do grau de alívio da angústia, é possível analisar indicadores da representação do padrão de apego implicada. Cada criança realizou o procedimento no mínimo duas vezes. No primeiro encontro foram acessados os indicadores do padrão de apego da criança em relação à mãe (ou o pai, conforme a escolha da criança) e, no segundo, após uma semana, em relação ao outro genitor. Crianças que incluíram outra figura de apego, que não seus pais, realizaram o procedimento três vezes.

No segundo encontro com os meninos foi utilizada a Escala Global e Escala de Freqüência de Sinais Específicos aplicada ao Desenho da Família ${ }^{30-31}$ que buscava levantar indicadores do padrão de apego da criança. Ao final do processo, foram realizadas Entrevistas de devolução com as famílias para trabalhar a indicação psicoterapêutica, conforme o caso. As entrevistas foram gravadas (em áudio e vídeo) e posteriormente transcritas, sob autorização.

A coleta dos dados, realizada pela primeira autora, ocorreu entre os meses de julho e outubro de 2007 e durou aproximadamente um mês para cada menino, tendo sido realizadas de seis a sete entrevistas com cada caso. Nas situações que exigiram filmagem e posterior transcrição, houve o auxílio de uma bolsista de iniciação científica.

O material coletado foi analisado por duas pesquisadoras, autoras desse artigo, em momentos distintos. Após, o conteúdo foi analisado pela dupla que discutiu os dados, considerando convergências e divergências, até chegar ao resultado final. Quando não houve consenso (o que ocorreu em um caso) um terceiro juiz (pesquisadora do grupo de pesquisa) participou da análise até se chegar ao resultado final.

As etapas seguidas para a análise dos dados foram baseadas no modelo de proposições teóricas de $\mathrm{Yin}^{27}$, que consta de cinco passos. No primeiro, todas as entrevistas foram transcritas; no segundo, os dados coletados através dos instrumentos foram interpretados e analisados com base nas instruções correspondentes; no terceiro, foi realizada uma descrição abrangente de cada caso, organizada de forma cronológica e temática.

A técnica de Construção da Explanação e Análise de Séries Temporais, na modalidade cronológica foi o quarto passo e buscou integrar os resultados dos instrumentos e os fatos marcantes da história que possam ter tido algum impacto sobre a configuração do apego, com a revisão bibliográfica, construindo assim uma hipótese acerca das configurações de apego da criança em relação a suas figuras parentais, em cada caso.

Por fim, no quinto passo foi utilizada a técnica de Síntese de Casos Cruzados, com o objetivo de confrontar os resultados obtidos na análise de cada caso em particular, identificando convergências e divergências e buscando, desta forma, evidências que auxiliassem a iden- 
tificar ou não a especificidade do padrão de apego em diferentes relações familiares.

\section{RESULTADOS E DISCUSSÃO}

Os nomes utilizados na apresentação dos casos, tanto para os meninos como para seus pais, são fictícios para preservar a identidade dos participantes.

\section{RÉGIS}

Trata-se de um menino de sete anos que vive com seus pais, Luisa (38a) e Luis (42a). Cursando a primeira série do ensino fundamental, mostrava-se bastante ansioso diante da possibilidade de seus pais não o encontrarem na saída da escola, o que havia se agravado nos últimos três meses. A gravidez foi organizada e planejada, especialmente pela mãe, que parou de trabalhar para dedicar-se completamente ao filho, acreditando que ele daria conta de seu sentimento de solidão. Mãe e filho mostraram-se muito próximos e Régis nunca havia se separado dos pais, nem mesmo para dormir na casa de familiares ou de amigos.

A história da mãe de Régis foi marcada por situações de maus-tratos, negligências, abandono e vulnerabilidade. Foi adotada com dois meses e, quando pequena, mudou-se diversas vezes. Casou-se jovem com Luis, que costumava ser agressivo e bater nela. Atualmente, o marido não apresenta mais este comportamento, no entanto mantém um relacionamento desgastado e sem intimidade. Quando Régis estava com cinco anos, Luisa engravidou novamente. Teve um aborto espontâneo com dois meses e, nesta ocasião, não foi apoiada pelo marido ou outros familiares.

Luis possui uma história de vida rígida e severa, com pais autoritários e distantes afetivamente. No decorrer da avaliação a insegurança e os temores do menino melhora- ram e ele começou aceitar a possibilidade de ir à casa dos familiares sem os pais. Essa nova conduta deixou especialmente a mãe aflita.

\section{LUAN}

No momento da avaliação Luan com cinco anos e 11 meses, estava na pré-escola e vivia com seus pais, Sonia (38a) e Pedro (40a) e sua irmã Tais (16a). A mãe procurou atendimento a partir do encaminhamento da pediatra e da escola, pelo fato de Luan demonstrar dificuldades de relacionamento. Com grande dificuldade em aceitar limites, batia nos colegas, era "respondão", agitado, evitava o colégio quando não conseguia o que desejava e não tinha paciência de esperar sua vez. Apresentava encoprese, o que foi resolvido mediante palmadas, xingamentos e, por último, conversa. Na época da avaliação estava apresentando enurese noturna e fazendo tratamento para asma.

Os pais de Luan namoraram por sete anos e resolveram "se assumir" quando Sonia engravidou inesperadamente da primeira filha. 10 anos após a primeira gestação planejaram ter Luan, sendo o período da gravidez do menino marcado pela instabilidade conjugal, conflitos, ameaças de separação por parte de Pedro e insegurança de Sonia. Os pais de Luan apresentam histórias familiares distintas e mostram-se bastante diferentes, quase sem afinidades entre eles.

Os principais fatores de risco da história da mãe relacionam-se ao abandono paterno, dificuldades financeiras com episódios de fome e frio. A família do pai tinha como característica marcante a rigidez afetiva, as crianças apanhavam e eram logo incentivadas a trabalhar. Quando Luan nasceu, a avó paterna estava com sérios problemas de saúde. Atualmente, seus pais possuem certa estabilidade financeira, mas já tiveram que conviver com o desemprego paterno. Ao longo das sessões, o menino se mostrou agitado e disperso, com dificuldade em cumprir com as atividades propostas durante a avaliação. 


\section{FREDY}

Fredy estava com oito anos no momento da avaliação, estudava na terceira série do ensino fundamental e vivia com seus pais, Mara (28a) e Adair (33a) e com sua irmã Eva (três a). Os pais procuraram atendimento após o encaminhamento da escola e de um psicólogo conhecido da família. O menino apresentava dificuldade de relacionamento, tinha a necessidade de chamar atenção, mostrava-se agitado, ciumento e precisava manter a luz acesa para dormir. Os pais mostravam-se irritados frente a estas situações, batendo e colocando o filho de castigo.

O casal teve um início de vida marcado por conflitos familiares significativos. As famílias não aprovavam o namoro, e por conta disso houve uma série de conflitos com as famílias de origem. A mãe de Fredy teve uma história de vida caracterizada por abandono materno e paterno, sendo criada por avós maternos, pessoas simples e pouco cuidadoras, e casou-se cedo na tentativa de sair desta situação desgastante. O pai do menino vem de uma família mais estruturada afetiva e financeiramente.

Mara se considera uma pessoa instável, com altos e baixos freqüentes, sentimentos que iniciaram depois do nascimento da segunda filha. Já fez tratamento para depressão e costuma fazer dietas, com uso de medicação. Trabalha durante o dia e refere não ter paciência com os filhos. Adair exerce atividade profissional juntamente com seu pai e nos finais de semana joga futebol com os amigos. O casal não apresenta muitos momentos íntimos ou em família e Fredy permanece grande parte do dia sob os cuidados da avó paterna. No decorrer da avaliação Fredy, assim como sua família, mostraram-se mais tranqüilos e interativos.

A análise dos três casos mostra histórias marcadas por diversos fatores de vulnerabilidade, o que corrobora a presença de indicadores de apego inseguro na maior parte dos vínculos avaliados. Conforme estudos ${ }^{4-5,8-9,719}$ realizados com diferentes classes sociais e nacionalidades distintas, as situações negativas de vida configuram-se como fatores de risco e vulnerabilidade e produzem modelos de apego não muito organizados, frágeis, instáveis e com grande probabilidade de se constituírem como padrões de apego inseguros e mais propensos à mudança.

$\mathrm{Na}$ presente pesquisa, em dois dos três casos foi possível levantar a hipótese de especificidade do padrão de apego em relação à mãe e ao pai. No caso de Luan, enquanto com a mãe predominaram indicadores relacionados ao apego evitativo, com o pai constataram-se indicadores de um padrão inseguro desorganizado.

Com o participante Fredy houve um predomínio de indicadores próximos ao apego inseguro evitativo, quando avaliada a relação com a mãe, e indicadores de apego seguro, com aspectos de restrição e evitação, no momento da avaliação em relação à figura paterna. Este menino incluiu a avó no procedimento, evidenciando frente a essa figura indicativos de um apego seguro, com aspectos de restrição e evitação. Já no caso de Régis, os indicadores do apego associaram-se ao padrão inseguro evitativo tanto em relação à mãe como ao pai, não se confirmando totalmente a hipótese de especificidade (Tabela 1).

Em todos os casos, entretanto, características distintas foram identificadas em cada relação parental, apontando variações significativas na qualidade do apego de cada díade. Nesse sentido, é pertinente considerar o aspecto da "reciprocidade da interação"12 que sustenta como as pessoas com indicadores de padrões de apego seguro podem encorajar outros a desenvolverem padrões de apego também seguros, assim como pessoas com indicadores de apego inseguro, em geral, influenciam negativamente "pessoas seguras", a ponto de elas modificarem o seu padrão de apego se a relação permanecer e for significativa. Enfim, para o autor, todas as relações são únicas e apresen- 
Tabela 1: Resultados do Manchester Child Attachment Story Task-MCAST

\begin{tabular}{|c|c|c|c|c|c|c|c|}
\hline & & Vinheta 1 & Vinheta 2 & Vinheta 3 & Vinheta 4 & Vinheta 5 & Predom.* \\
\hline \multirow[b]{2}{*}{ Régis } & Mãe & $\begin{array}{l}\text { altamente } \\
\text { evitativo }\end{array}$ & seguro & seguro & $\begin{array}{l}\text { altamente } \\
\text { evitativo }\end{array}$ & $\begin{array}{l}\text { levemente } \\
\text { evitativo }\end{array}$ & evitativo \\
\hline & Pai & $\begin{array}{l}\text { altamente } \\
\text { evitativo }\end{array}$ & $\begin{array}{l}\text { seguro } \\
\text { restr e evit** }\end{array}$ & $\begin{array}{l}\text { altamente } \\
\text { evitativo }\end{array}$ & $\begin{array}{l}\text { altamente } \\
\text { evitativo }\end{array}$ & $\begin{array}{l}\text { levemente } \\
\text { evitativo }\end{array}$ & evitativo \\
\hline \multirow[b]{2}{*}{ Luan } & Mãe & $\begin{array}{l}\text { altamente } \\
\text { evitativo }\end{array}$ & $\begin{array}{c}\text { seguro } \\
\text { restr e evit }\end{array}$ & $\begin{array}{l}\text { levemente } \\
\text { evitativo }\end{array}$ & $\begin{array}{l}\text { altamente } \\
\text { evitativo }\end{array}$ & $\begin{array}{l}\text { levemente } \\
\text { evitativo }\end{array}$ & evitativo \\
\hline & Pai & $\begin{array}{l}\text { impossível } \\
\text { classificar }\end{array}$ & $\begin{array}{c}\text { organização } \\
\text { difusa }\end{array}$ & $\begin{array}{c}\text { organização } \\
\text { difusa }\end{array}$ & $\begin{array}{l}\text { altamente } \\
\text { evitativo }\end{array}$ & $\begin{array}{l}\text { altamente } \\
\text { evitativo }\end{array}$ & evitativo \\
\hline \multirow{2}{*}{ Fredy } & Mãe & $\begin{array}{l}\text { altamente } \\
\text { evitativo }\end{array}$ & ambivalente & ambivalente & $\begin{array}{l}\text { levemente } \\
\text { evitativo }\end{array}$ & $\begin{array}{l}\text { altamente } \\
\text { evitativo }\end{array}$ & evitativo \\
\hline & Pai & ambivalente & $\begin{array}{c}\text { seguro } \\
\text { restr e evit** }\end{array}$ & $\begin{array}{c}\text { seguro } \\
\text { restr e evit }\end{array}$ & $\begin{array}{l}\text { levemente } \\
\text { evitativo }\end{array}$ & $\begin{array}{l}\text { seguro } \\
\text { restr e evit } * *\end{array}$ & $\begin{array}{c}\text { seguro } \\
\text { restr e evit** }\end{array}$ \\
\hline
\end{tabular}

* Predom. significa o indicador do padrão de apego predominante para cada relação.

** seguro-restr e evit significa que o padrão de apego apresentou indicadores de apego seguro, mas com aspectos de restrição e evitação.

tam o mesmo grau de importância, independente do grau de parentesco.

Os resultados deste estudo foram obtidos prioritariamente através do Manchester Child Attachment Story Task-MCAST e as hipóteses levantadas foram complementadas pelos resultados encontrados no Desenho da Família e no Medical Outcomes Study - MOS. Dos três casos avaliados, Luan foi aquele que apresentou maior comprometimento e, nesse caso, a Escala de Frequência de Sinais Específicos e Escala Global, aplicadas ao Desenho da Família, apresentaram 11 sinais específicos indicadores de apego inseguro. Além disso, o desenho de Luan mostrou-se bizarro e extremamente empobrecido, as pessoas estavam "voando" e não representavam os membros de sua família.

No caso de Régis, a Escala de Freqüência de Sinais Específicos e Escala Global, aplicadas ao Desenho da Família, apresentaram seis indicadores de padrão de apego inseguro. Nesse procedimento, Régis inseriu o pai no desenho "para este não ficar chateado", como se fosse uma obrigação esse contato, o que pode reforçar a hipótese de maior proximidade do menino com a mãe.

Com Fredy, a análise da Escala de Freqüência de Sinais Específicos e da Escala Glo- bal, aplicadas ao Desenho da Família, indicou 8 sinais específicos de apego inseguro. Constatou-se que o menino desenhou primeiramente a avó paterna e o pai e, por último a mãe, podendo indicar um distanciamento afetivo maior em relação à figura materna.

Se os fatores de vulnerabilidade e de desorganização familiar implicam em risco para a formação de padrões de apego inseguro, a literatura também aponta que quanto maior a rede de apoio social, a estabilidade e a continência familiar, maior a tendência da formação de padrões de apego seguro, com prevalência de atitudes autônomas e auto-estima elevada, haja vista a necessidade dos indivíduos recorrerem a pessoas significativas e de confiança quando em sofrimento ${ }^{1-2,20-22}$. O suporte é ainda mais efetivo quando realizado por pessoas da família, do que entre pares, sendo que a falta desta rede de apoio, somada ao baixo status sócio-econômico pode aumentar o índice de padrões de apego inseguro ${ }^{3,15}$.

Em relação aos resultados do MOS, constatou-se que a percepção dos pais e mães nos três casos avaliados foi de uma rede de apoio e da qualidade do apoio social disponível, moderada ou total. Embora a literatura relacione o apoio social com o apego seguro ${ }^{20-21}$, 
32-34, foi levantada a hipótese de que, na realidade das famílias avaliadas, a existência dessa rede por si só não foi suficiente para assegurar vínculos de apego seguro. As adversidades e os fatores de risco presentes na história de vida dessas famílias parecem ter um peso significativo, que a rede de apoio não se mostrou suficiente para neutralizar.

Uma metaanálise sobre a especificidade do apego ${ }^{13}$ foi desenvolvida e as conclusões indicaram que a formação do padrão de apego seguro ou inseguro com um dos pais influenciava o estabelecimento do mesmo tipo de padrão com o outro progenitor. Anos mais tarde, outras pesquisas com populações predominantemente européias ${ }^{14,16}$ chegaram às mesmas conclusões, afirmando que existe uma tendência do padrão de apego menos estável ser influenciado pelo mais estável durante o desenvolvimento do sujeito.

Por outro lado, alguns estudos afirmam que o padrão de apego seguro, formado na relação com a figura materna, tende a se manter estável ao longo do tempo e, assim, influenciar mais fortemente as relações futuras quando comparado ao padrão de apego seguro constituído na relação com a figura paterna, considerado mais instável e sujeito a mudanças ao longo do tempo ${ }^{10-11,24-26}$. Ainda, os conflitos conjugais podem abalar negativamente a constituição do padrão de apego da criança em relação ao pai, mas nada interferir na formação do padrão de apego do filho com a mãe, na mesma situação ${ }^{10}$. O estudo em questão não se configura como uma pesquisa longitudinal, portanto, não existe a possibilidade deste aspecto ser verificado.

No entanto, os resultados indicaram que no caso de Régis e Luan, apesar do padrão de apego constituído em relação à figura materna indicar um apego inseguro evitativo, também foi constatado que, nestas situações, a qualidade da relação foi melhor, ou seja, de maior proximidade, quando comparada à qualidade da relação com a figura paterna. No caso de Régis, as estórias narradas em relação à mãe possibilitaram o brincar, a exploração do ambiente e demonstraram alívio da angústia em diversos momentos. Já com o pai tais atitudes não foram visíveis e o menino introduziu a mãe durante a narrativa.

Com Luan, quando avaliada a relação com a mãe, apesar dos desfechos serem negativos, houve uma construção de estória que não ocorreu quando avaliada a relação com o pai. $\mathrm{Na}$ avaliação relativa à representação do apego paterno houve uma desorganização do menino diante da angústia, com falas incoerentes, conteúdos confusos, além da introdução da mãe nas estórias.

No caso de Fredy este achado não foi identificado, o que pode ser justificado pelo comprometimento emocional de sua mãe que se mostrou, em diversos momentos, incapaz de cuidar, acolher e conter o filho. Este participante introduziu a avó no procedimento e, nesta relação, foram avaliados indicadores de apego seguro, com aspectos de restrição e evitação. Além disso, ao contar estórias relacionadas às figuras da mãe e do pai, Fredy introduziu a avó nas narrativas.

As considerações acima podem indicar que não só a relação com a mãe, mas sim a relação estabelecida com o cuidador principal (em geral a mãe, mas que pode ser também a avó, o pai ou outros) é muito significativa. Essa relação pode apresentar mais qualidade e, quem sabe, mais estabilidade quando comparada com as outras relações.

O fato das três crianças avaliadas apresentarem predominantemente padrões de apego com indicadores evitativos pode estar relacionado às dificuldades que os pais apresentaram em servir como base segura e dar a oportunidade dos filhos explorarem tanto seu ambiente externo, como seu próprio mundo interno. $\mathrm{O}$ apego evitativo está relacionado a uma falta de responsividade contingente por parte dos cuidadores e, às vezes, a condutas superprotetoras da parte deles ${ }^{35}$. Tal funcionamento gera nos filhos falta de autonomia e au- 
toconhecimento e conseqüentemente incapacidade de mobilizar recursos e amadurecer para enfrentar os problemas e adversidades.

Desta maneira, a tendência das crianças neste estudo foi evitar os conflitos e a angústia despertada em cada situação vivenciada. Fredy foi o único que conseguiu, ainda que sutilmente, diferenciar-se um pouco deste funcionamento, em grande parte porque a avó paterna foi uma figura de apego que, além de possibilitar os recursos, estimulava a autonomia do menino.

A Tabela 1 apresenta os resultados obtidos nos 3 casos, em relação aos indicadores dos padrões de apego das crianças, conforme o MCAST.

\section{CONSIDERAÇÕES FINAIS}

Diante do exposto, evidencia-se que a identificação dos indicadores dos padrões de apego das crianças em relação às suas figuras parentais apontou para a existência de elementos específicos do padrão de apego correspondentes a cada relação com essas figuras. As características familiares descritas pela literatura como associadas a um padrão de apego seguro, relacionadas a um ambiente estável, pais com bom relacionamento conjugal e efetiva rede de apoio e social não foram identificadas nos casos avaliados. Já os aspectos identificados relativos ao apego inseguro foram àqueles relacionados a problemas na família tais como: depressão materna, doenças crônicas, instabilidade financeira e conflitos conjugais. Deve-se salientar que esse não é um resultado inesperado, já que se trata de uma população clínica.

Os resultados dos instrumentos e das entrevistas realizadas demonstraram variações no apego para cada relação avaliada. Apesar da existência de um padrão de apego predominante em relação à figura materna ou paterna e semelhante em ambas relações, aspectos de outros padrões de apego também foram identificados numa mesma relação, levantando-se a hipótese de que os padrões de apego na infância não constituem uma unidade e podem coexistir com elementos correspondentes aos outros padrões. A existência de padrões de apego seguros com aspectos inseguros e vice-versa sinalizaram para esta possibilidade.

O aprofundamento teórico acerca desta temática permitiu identificar que as pesquisas realizadas têm se preocupado principalmente em avaliar o padrão de apego. Considera-se importante pensar numa continuidade clínica, ou seja, o que fazer com isso? Um dos pontos fundamentais da pesquisa, no campo da Psicologia Clínica, é a possibilidade de aliar os achados científicos com a prática e aplicação clínica. Entende-se que a possibilidade de pensar sobre a especificidade do padrão de apego em diferentes relações emocionalmente significativas pode contribuir para trabalhos preventivos, promocionais de vínculos seguros e interventivos, no sentido de alterar um padrão eventualmente inseguro.

A realização desse estudo permitiu constatar a falta de instrumentos brasileiros para avaliação do apego tanto em crianças e adolescentes quanto em adultos. Também se salienta a necessidade de estudos sobre a especificidade e a variabilidade do apego em nosso país, além de pesquisas que focalizem populações não clínicas.

Deve-se destacar algumas limitações desse estudo: o fato de ter sido realizado apenas com meninos, apontando para a necessidade de investigações semelhantes com meninas e com crianças de outras faixas etárias. A exploração desse foco considerando as variáveis de nascimento das crianças, por exemplo, também poderá oferecer subsídios importantes para trabalhos preventivos com essa população.

Merece destaque, finalmente, as implicações clínicas que a hipótese da especificidade e da variabilidade do apego possui, no sentido das possibilidades que abrem no trabalho psicoterapêutico com esses pacientes. Sem dúvida o tema do apego é de grande complexidade, e apesar das adversidades encontradas trata-se de um campo fértil, com relevância clínica e teórica, que merece ser cada vez mais aprofundado. 


\section{REFERÊNCIAS}

1. Davila J, Cobb RJ. Predicting change in self-reported and interviewer-assessed adult attachment: testes of the individual difference and life stress models of attachment change. PSPB. 2003;29(7):859-870.

2. López F. Apego: estabilidad Y cambio a lo largo del ciclo vital. Infancia y Aprendizaje 2006;29(1):9-23.

3. Schneider BH. ¿Cuánta estabilidad en los estilos de apego está implícita en la teoría de Bowlby?: comentario al artículo de Félix López. Infancia y Aprendizaje. 2006;29(1):25-30.

4 Theran SA., Levendosky AA, Bogat GA, Huth-Bocks AC. Stability and change in mothers' internal representations of their infants over time. Attach Hum Dev. 2005;7(3):253-268.

5. Zhang F, Labouvie-vief G. Stability and fluctuation in adult attachment style over a 6-year period. Attach Hum Dev. 2004;6(4):419-437.

6. Waters E, Hamilton CE, Weinfield NS. The stability of attachment security from infancy to adolescence and early adulthood: general introduction. Child Dev. 2000a; 71(3):678-683.

7. Waters E, Weinfield NS, Hamilton CE. The stability of attachment security from infancy to adolescence and early adulthood: general discussion. Child Dev. 2000b;71(3):703-706.

8. Waters E, Merrick S, Treaboux D, Crowell J, Albershein L. Attachment Security in Infancy and Early Adultohhod: A TwentyYear Longitudinal Study. Child Dev. 2000;71(3):684-689.

9. Weinfield NS, Sroufe LA, Egeland B. Attachment from infancy to early adulthood in a high-risk sample: continuity, discontinuity, and their correlates. Child Dev. 2000;71(3):695702.

10. Caldera YM, Lindsey EW. Coparenting, mother-infant interaction, and infantparent attachment relationships in twoparent families. J Fam Psychol. 2006;20(2):275-283.

11. Carranza LV, Kilmann PR. Links between perceived parent characteristics and attachment variables for young women from intact families. Adolescence. 2000;35(138):295-312.

12. Cook WL. Understanding Attachment Security in Family Context. J Pers Soc Psychol. 2000;78(2):285-294.

13. Fox NA, Kimmerly NL, Schafer WD. Attachment to mother/attachment to father: a meta-analysis. Child Dev. 1991;62:210-225.

14. Furman W, Simon VA. Concordance in attachment states of mind and styles with respect to fathers and mothers. Dev Psychol. 2004;40(6):1239-1247.

15. Imamoglu S, Imamoglu EO. Relationship between general and context-specific attachment orientations in a turkish sample. J Soc Psychol. 2006;146(3):261274.

16. Sánchez-Queija I, Oliva A. Vínculos de apego con los padres y relaciones con los iguales durante la adolescencia. Rev Psicol Social. 2003;18(1):71-86.

17. Bowlby J. Apego e perda. Vol 1. Apego: a natureza do vínculo. São Paulo: Martins Fontes; 2002 (Original publicado em 1969).

18. Bowlby J. Apego e perda. Vol 2. Separação: angústia e raiva. São Paulo: Martins Fontes; 1998a (Original publicado em 1973).

19. Lewis M, Feiring C, Rosenthal S. Attachment over time. Child Dev. 2000;71(3):707-720.

20. Cronckenberg S. Infant irritability, mother responsiveness and social support 
influences on the security of infant-mother attachment. Child Dev. 1981;52:857-869.

21. Jacobson S, Frye K. Effect on maternal social support on attachment: experimental evidence. Child Dev. 1991;62:572-582.

22. Sánchez NV. Consideraciones acerca de los estilos de apego y su repercusión en la prática clínica. In: V Congreso Sudamericano de Investigación en Psicoterapia Empírica y III Encuentro Psicoterapéutico; 2002 Ago; Reñaca, Viña del Mar.

23. Ainsworth MDS. Attachments Beyond Infancy. Am Psychol. 1989;44(4):709-716.

24. Berlin LJ, Cassidy J. Relations among relationships: contributions from attachment theory and research. In: Cassidy J, Shaver PR, editors. Handbook of Attachment: Theory, Research and Clinical Applications. New York: The Guilford Press; 1999. p. 688-712.

25. Cassidy J. The nature of the child's ties. In: Cassidy J, Shaver PR, editors. Handbook of Attachment: Theory, Research and Clinical Applications. New York: The Guilford Press; 1999. p. 3-20.

26. Main M, Kaplan N, Cassidy J. Security in Infancy, Childhood, and adulthhood: a move to the level of representation. In: Bretherton I, Waters E, editors. Growing points of attachment theory and research Monografhs of the Society for Research in Chile Development. 1985;50(1-2, Serial $n^{\circ}$ 209):66-106.

27. Yin RK. Estudo de caso: planejamento e métodos. Porto Alegre: Bookman; 2003.

28. Green J, Stanley C, Smith V, Goldwyn R. A new method of evaluating attachment representations in young school-age children: The Manchester Child Attachment Story Task. Attach Hum Dev. 2000;2(1):48-70.
29. Chor D, Griep RH, Lopes CS, Faerstein E. Medidas de rede e apoio social no estudo pró-saúde: pré-testes e estudo piloto. Cad Saúde Pública. 2001;17(4):887-896.

30. Fury G, Carlson EA, Sroufe LA. Children's representations of attachment relationships in family drawings. Child Dev. 1997;68(6):1154-1164.

31. Cecconello AM, Koller SH. Avaliação da representação mental da relação de apego através do desenho da família: um estudo com crianças brasileiras. Arq Bras Psicol. 1999;51(4):39-51.

32. Ávila SC, Maldonado C, Saldarriaga LM, Veja L, Diaz S. Patrones de Apego em Familias de três generacionaes: abuela, madre adolescente, hijo. Rev Latinoamericana Psicol. 2004;36(3):409430.

33. Harvey M, Byrd M. Relationships between adolescents' attachment styles and family functioning.

Adolescence. 2000;35(138):345-356.

34. Mayer LR. Rede de apoio social e representação mental das relações de apego de meninas vítimas de violência doméstica (tese de doutorado não publicada). Porto Alegre: Universidade Federal do Rio Grande do Sul; 2002.

35. Bretherton I, Munholland KA. Internal working models in attachment relationships: a construct revisited. In: Cassidy J, Shaver PR, editors. Handbook of Attachment: Theory, Research and Clinical Applications. New York: The Guilford Press; 1999. p. 89-111.

Recebido em: 08/ago./2010 Modificado em 26/nov./2010 Aceito em 16/mar./2011 